\title{
Implementation of the WHO Multimodal Hand Hygiene Improvement Strategy in a Tertiary Academic Hospital in Rwanda
}

Hakizimana $\mathbf{B}^{1,2 *}$

${ }^{1}$ Academic Unit for Infection Prevention and Control, Faculty of Medicine and Health Sciences, Stellenbosch University, P.O. Box 19063, Tygerberg 7505, Cape Town, South Africa

${ }^{2}$ Infection Prevention and Control Department, University Teaching Hospital of Butare (CHUB), Huye District, The Republic of Rwanda

\begin{abstract}
Background: Hands of healthcare personnel are known to be the main route of cross transmission of pathogens in healthcare facilities and it is known that hand hygiene is the most effective preventive measure against healthcareassociated infections (HAls). WHO Hand Hygiene Improvement Strategy is being implemented in a University Teaching Hospital of Butare (CHUB) since November 2011 to improve patients and staffs safety.

Methods: This quasi-experimental study was conducted in Butare University Teaching Hospital, a tertiary academic hospital, between November 2011 and November 2015. We implemented the WHO's Multimodal Hand Hygiene Improvement Strategy and assessed the compliance of hand hygiene before and after the interventions. The entire project included five steps: (1) facility preparedness, (2) baseline evaluation, (3) implementation, (4) follow-up evaluation, and (5) on-going planning and review cycle. Baseline evaluation of multimodal hand hygiene self-assessment and hand hygiene compliance was performed, using the WHO Multimodal Hand Hygiene SelfAssessment Framework tool and the WHO's direct observation method. Data was analysed using Ms Excel.

Results: The baseline hand hygiene compliance was measured at $6.25 \%$. The Hand Hygiene Level of the hospital was 100 at the baseline, which means inadequate level. The intervention was conducted during 2012 and 2013 and it included provision of hand hygiene supplies, training of healthcare workers, and display of reminders in the workplace. The post intervention hand hygiene programme evaluation was conducted in 2015. Hand hygiene audit was conducted in 6 wards (Neonatology, Intensive Care Unit, Paediatrics, Surgical, Internal Medicine and Gynaeco-Obstetrics) and revealed an average score of $20.86 \%$. There were 58 hand hygiene actions from 278 hand hygiene opportunities, with an average of 46 hand hygiene opportunity per ward. The compliance ranged from $1.9 \%$ (Internal Medicine) to $57.8 \%$ (ICU). An improvement of $14.61 \%$ of hand hygiene practice $(6.25 \%$ in 2012 to $20.86 \%$ in 2015) was noted. Alcohol-based hand rub (ABHR) was the most used procedures and it was used in $89.66 \%$ $(52 / 58)$ of performed indications. Hand hygiene practice among professional categories was $24.6 \%(33 / 134)$ actions for nurses' opportunities, $22.7 \%$ (25/110) actions for medical doctors and there was no action among allied health professionals $(0 / 8)$ or caretakers (0/26). Hand hygiene self-assessment tool was completed and the score was 355 which mean intermediate level. 60.46\% (159/263) of hand washing basins were in good conditions (means working and not damaged) and availability of water was $40.30 \%(106 / 263)$.

Conclusion: It is feasible and possible to implement WHO Hand Hygiene Improvement Strategy even in healthcare facilities with limited resources. The findings from the study showed the improvement from the basic level to intermediate level of hand hygiene and improvement in hand hygiene compliance of $14.61 \%$ (from $6.25 \%$ to $20.68 \%$ ) in three year period. There is a need to continue with the implementation of the WHO Multimodal Hand Hygiene Improvement Strategy by sustaining what have been achieved and putting more effort in areas of improvement such developing SMART plans for staff training and education, patient involvement and infrastructure improvement plan.
\end{abstract}

Keywords: WHO hand hygiene improvement strategy; Hand hygiene audit; Hand hygiene compliance; Hand hygiene self-assessment framework; Hand hygiene level; Alcohol-based hand rub (ABHR); Hand washing basin; Healthcare-associated infections (HAI); African partnership for patient safety

\section{Introduction}

Healthcare-associated infection (HAI) is defined as: "An infection occurring in a patient during the process of care in a hospital or other health-care facility which was not present or incubating at the time of admission. This includes infections acquired in the hospital, but appearing after discharge and also occupational infections among staff of the facility [1].

HAI is the most frequent result of unsafe patient care and it is among the most important challenges of healthcare systems worldwide [2-5]. It is a major problem for patient safety and its impact can result in prolonged hospital stay, long-term disability, and increased resistance of microorganisms to antimicrobial agents, a massive additional financial burden for the health system, high costs for patients and their families, and excess deaths [6,7]. Of every 100 hospitalized patients at any given time, seven in developed and 15 in developing countries will acquire at least one HAI. The endemic burden of HAI is also significantly (at least 2-3 times) higher in low- and middle-income countries (LMICs) than

*Corresponding author: Boniface Hakizimana, Academic Unit for Infection Prevention and Control, Faculty of Medicine and Health Sciences, Stellenbosch University, P.O. Box 19063, Tygerberg 7505, Cape Town, South Africa, Tel: +250788594903; E-mail: bonihak@yahoo.fr

Received: May 28, 2018; Accepted: June 04, 2018; Published: June 10, 2018

Citation: Hakizimana B (2018) Implementation of the WHO Multimodal Hand Hygiene Improvement Strategy in a Tertiary Academic Hospital in Rwanda. J Infect Dis Med 3: 126. doi: 10.4172/2576-1420.1000126

Copyright: ( 2018 Hakizimana B. This is an open-access article distributed under the terms of the Creative Commons Attribution License, which permits unrestricted use, distribution, and reproduction in any medium, provided the original author and source are credited. 
in high-income nations, particularly in patients admitted to intensive care units, and neonates [8]. Hands of healthcare personnel are known to be the main route of cross transmission of pathogens in healthcare facilities, and, as stated by the World Health Organization (WHO) and Centres for Disease Control and Prevention (CDC), hand hygiene is the most effective preventive measure against HAIs. Nonetheless, hand hygiene compliance among healthcare workers is not acceptable, below $40 \%$ globally $[4,9-11]$. Hand hygiene has become a major issue of patient safety [12]. In addition to being a key element in standard precautions, hand hygiene has emerged as an important component in specific site infection prevention recommendations recently [13]. In accordance with the first Global Patient Safety Challenge, the WHO published important instructions including guidelines on hand hygiene in healthcare, implementation of the WHO Multimodal Hand Hygiene Improvement Strategy, and Hand Hygiene technical reference manual $[14,15]$. The aim of these guidelines is to improve hand hygiene practices worldwide by creating a unified description for hand hygiene methods, right moments, and observation process and present multimodal strategies for improvement [14-17].

The WHO Hand Hygiene Improvement Strategy is being implemented in a University Teaching Hospital of Butare (CHUB) since November 2011. This is a 500 bedded Tertiary Academic Hospital which opened its doors in 1928 and is based in the Southern Province of Rwanda. The hospital has been benefited from the WHO project named: African Partnership for Patient Safety (APPS) which is concerned with strengthening patient safety structures and systems in healthcare institutions across the WHO Region of Africa. The programme aims to increase awareness of patient safety using a common entry point of healthcare associated infections (HAIs). In addition APPS aims to improve practices in healthcare in the African hospital by supporting and developing partnerships between hospitals in Europe and the WHO Region of Africa [18]. CHUB was linked to and assisted by Imperial College Healthcare NHS Trust (ICHNT) of London during a period of two years since November 2011 to October 2013. During that period, the exchange visits were conducted by both ICHNT and CHUB teams and knowledge was transferred to both sides. CHUB team had been trained on how to conduct hand hygiene self-assessment of the facility and hand hygiene audit. Apart from hand hygiene self-assessment framework, both technical and financial support were provided to CHUB by training of the pharmacy team on local production of alcohol-based handrub (ABHR) and providing funds for supplying of required ingredients and materials that helped to start the locally-made alcohol-based handrub WHO formulation [1].

\section{Methods}

This quasi-experimental study was conducted in Butare University Teaching Hospital, a tertiary academic hospital, between November 2011 and November 2015. It is the largest hospital in the Southern Province of Rwanda and a referral hospital for neighbouring district hospitals with 500 beds including 418 beds actively in use in 14 wards including surgical emergency, intensive care (mixed), surgical, internal medicine, paediatrics, gynaeco-obstetrics, dermatology, ophthalmology, earnose-throat, stomatology, postoperative recovery, clinics, dialysis and TB isolation. We implemented the WHO's Multimodal Hand Hygiene Improvement Strategy and assessed the compliance of hand hygiene before and after the interventions.

The Multimodal Hand Hygiene Improvement Strategy consists of five key elements that are (1) system change to ensure access of healthcare workers to hand hygiene facilities with emphasis on availability of alcohol-based hand rub (ABHR) formulations at the point of care,
(2) on-going training and education, (3) evaluation of practices and feedback, (4) reminders at the workplace, and (5) providing a climate of safety through institution.14.

The entire project included five steps: (1) facility preparedness, (2) baseline evaluation, (3) implementation, (4) follow-up evaluation, and (5) on-going planning and review cycle.14.

In step (1), the facilities were prepared. The human and financial resources were obtained, key leadership and its deputy were identified, sources were evaluated, and the strategy for the whole program was clearly defined. Hand washing basins were inadequate (at least one hand washing basin for up to 10 beds) and there was no soap, or paper towels available. Alcohol (ethanol) diluted locally in the hospital pharmacy, was available in some wards, however, its efficacy and tolerability were not proved. There was no educational session on hand hygiene provided for staff.

Baseline evaluation of multimodal hand hygiene self-assessment and hand hygiene compliance was performed, using the WHO Multimodal Hand Hygiene Self-Assessment Framework tool and the WHO's direct observation method. The Hand Hygiene Self-Assessment Framework is divided into five components and 27 indicators. The five components reflect the five elements of the WHO Multimodal Hand Hygiene Improvement Strategy (http://www.who.int/gpsc/5may/tools/ en/index.html) and the indicators have been selected to represent the key elements of each component. These indicators are based on evidence and expert consensus and have been framed as questions with defined answers (either "Yes/No" or multiple options) to facilitate self-assessment. Based on the score achieved for the five components, the facility is assigned to one of four levels of hand hygiene promotion and practice: Inadequate, Basic, Intermediate and Advanced. While completing each component of the Hand Hygiene Self-Assessment Framework, the investigator should circle or highlight the answer appropriate to the facility for each question. Each answer is associated with a score. After completing a component, the investigator adds up the scores for the answers he/she has selected to give a subtotal for that component. During the interpretation process these subtotals are then added up to calculate the overall score to identify the hand hygiene level to which the health-care facility is assigned. When the overall score of the healthcare facility is between 0 and 125, the 'Hand Hygiene Level' for the facility is inadequate. When the overall score of the healthcare facility is between 126 and 250, the 'Hand Hygiene Level' for the facility is basic. When the overall score of the healthcare facility is between 251 and 375, the 'Hand Hygiene Level' for the facility is intermediate and while the overall score of the healthcare facility is between 376 and 500, the 'Hand Hygiene Level' for the facility is advanced. The inadequate level means that hand hygiene practices and hand hygiene promotion are deficient and significant improvement is required. The basic level means that some measures are in place, but not to a satisfactory standard and further improvement is required. The intermediate level means that an appropriate hand hygiene promotion strategy is in place and hand hygiene practices have improved. It is now crucial to develop longterm plans to ensure that improvement is sustained and progresses. The advanced level means that hand hygiene promotion and optimal hand hygiene practices have been sustained and/or improved, helping to embed a culture of safety in the health-care setting.

As the direct observation method is time-consuming and also due to the lack of sufficient personnel, we randomly selected 6 wards from 14 wards. Observation sessions were performed by one Infection Prevention and Control Specialist and two nurses who were working 
as infection prevention and control practitioners and were trained to do so. This was a two days training course consisted of 2 parts. The first part consisted with theoretical knowledge transfer, whereby WHO's training Power Point slides for observers were taught during a period of one day and it covered WHO Multimodal Hand Hygiene Improvement Strategy and direct observation of hand hygiene practices. The second part was the practical exercises to enable trainees to develop skills on how to conduct both hand hygiene self-assessment of the hospital and how to conduct hand hygiene audit by using direct observation method.

The WHO's direct observation form is based on "My Five Moments for hand hygiene" that consists of the following: before patient contact, before aseptic procedure, after body fluid exposure risk, after patient contact, and after contact with patient surroundings as hand hygiene indications [15]. A positive or negative hand hygiene action, whether hand washing or hand rubbing, was recorded provided that it related to an indication. Opportunity is defined as the time hand hygiene should happen and it must relate to at least one hand hygiene indication. The compliance is calculated by dividing positive actions by opportunities. Hand hygiene practice of healthcare workers was monitored in 60-minute sessions. All categories of HCWs present in a ward at the time of the audit were observed for hand hygiene practice. These included nurses, doctors, Allied Health Professionals and Auxiliaries (House Keeping Staff). In the neonatology and paediatrics wards, the mothers of babies/infants were observed for hand hygiene. The average number of observed opportunities was 46 per ward. Performance feedback was given to the In-charges and Matrons in each ward area at the completion of the audit and a final report was consolidated to the hospital management, heads of departments, matrons and in-charges. Table-round discussions were held in each department and ward improvement plan developed.

In step (3), the improvement program was implemented. Pocketsize bottles for ABHR were supplied and ABHR (WHO formulation 1) produced locally and provided. In the same way, ABHR $500 \mathrm{ml}$ capacity bottles were placed at each treatment, surgical and emergency tray and thus alcohol-based ABHR became available at the point of care. Paper towels were supplied and became available at each hand washing basin (where it does exist). Visual hand hygiene color posters in different sizes were provided that showed the five moments for hand hygiene and right techniques. Posters were placed in the most visible places in wards (in front of nursing stations) and next to each hand washing basin (poster for hand washing).

Hand hygiene training was given to all clinical staff (nurses, doctors and allied health professionals) in 2012 and ongoing training in hand hygiene and infection prevention and control planned to be run each year. The content was based on WHO's training slides. Teaching rounds were conducted with emphasis on intensive care units due to lower compliance rate according to prior studies [5,19-21]. In these rounds, five moments for $\mathrm{HH}$ and right techniques were practiced.

In step (4), after 12 months and 36 months respectively, follow-up evaluation for assessment of program effectiveness was performed. Observation feedback was announced to each matron and ward incharge at the completion of the assessment. Presentation of findings at ward level followed by improvement plan development was conducted in each department. A hospital-wide roundtable presentation and discussion of findings was organized and presided by the Director General of the hospital.

Data was analysed using Ms Excel.

\section{Results}

A baseline audit of hand hygiene facilities and practice was completed on 9 patient ward areas and 5 treatment areas (Table 1). In most wards there was no sink, and if present, it often did not have soap or hand towels. Alcohol-based hand rub was available but the supply was limited and so there may be only 1 container for a 16 bed area. The use of alcohol spray made it difficult to deliver sufficient alcohol for hand hygiene and the preparation made by pharmacy did not contain emollients.

The baseline hand hygiene compliance was conducted on 16 May 2012 and was measured at $6.25 \%$ based on 32 opportunities of hand hygiene that were observed on a range of wards in the hospital (Table 2). The use of clinical gloves was observed to be widespread and to interfere with hand hygiene as gloves are put on to deliver care, frequently not changed between patient contacts, and hands not decontaminated before or after gloves are put on or taken off. The lack of hand hygiene facilities supports this practice. The WHO Hand Hygiene Self-Assessment tool was completed and gave CHUB a baseline score of 100 that means that Hand Hygiene Level for the facility was inadequate. An action plan to address the availability of hand hygiene facilities has been developed and it included: distribution of portable wash hand sinks to the clinical areas that currently have no sink or running water; organise and commence production of formulation of WHO alcohol based hand rub (including identifying a supplier of pump dispenser bottles and wall brackets (ideally) and glycerol/ hydrogen peroxide and, calculation of the required production volumes using the WHO tool or calculating volumes required); Organise the purchase of disposable paper hand towels and wall mounted dispensers; make liquid soap available at all sinks (replacing Dettol which is currently in use and causes adverse skin reactions) 33; replace gluteraldhyde and chlorhexidine/cetrimide solutions with detergent solution for cleaning equipment prior to reprocessing in central sterile services. These changes resulted in financial savings which were used to sustain the supply of soap, alcohol rub and paper towels. The hospital management used funds from WHO African Partnership for Patient Safety and donations from the partnership between the Saint Francis Xavier University (STFX) Canada and CHUB entitled "PARTNERSHIP IN CARING" project for supplying of necessary hand hygiene supplies and facilities such as portable hand washing sinks (KANDAGIRUKARABE and Veronica buckets), liquid soap, pocketsize bottles for alcohol-based handrub, disposable towel papers, towel paper dispensers, wall-mounted alcohol-based handrub dispensers, ingredients for local production of alcohol-based handrub (Ethanol 95\%, Hydrogen peroxide 3\%, Glycerine and Sterile distilled water). The WHO hand hygiene reminder posters were printed and displayed wherever required. Hand hygiene and infection prevention and control training was developed and provided to all clinical and non-clinical

\begin{tabular}{|c|c|c|c|c|c|c|c|c|c|}
\hline No. of beds & $\begin{array}{c}\text { No. of } \\
\text { rooms }\end{array}$ & No. of HCW & $\begin{array}{c}\text { Hand rub } \\
\text { in reach }\end{array}$ & HWB & Water & Soap & Towel & Hand rub & $\begin{array}{l}\text { No. of HCW } \\
\text { with ABHR }\end{array}$ \\
\hline 101 & 9 & 44 & 0 & 5 & 2 & 1 & 1 (F) & 6 & 1 \\
\hline \multicolumn{8}{r}{} \\
\hline \multicolumn{8}{r}{ F: Fabric Towel; HCW: Healthcare Workers; HWB: Hand Washing Basin; ABHR: Alcohol-Based Hand Rub } \\
\hline
\end{tabular}

Table 1: Hand hygiene facilities audit at CHUB: 16 May 2012. 
staff. On 25 August 2013, the IPC team in collaboration with Hygiene Committee conducted the assessment of hand hygiene improvement achieved during the past one year of implementation of WHO Hand Hygiene Improvement Strategy by completing Hand Hygiene Selfassessment tool and gave the hospital a score of 227.5, and the Hand Hygiene Level for the facility improved from inadequate to basic level (Table 3). There was no hand hygiene programme evaluation done in 2014. The post intervention hand hygiene programme evaluation was conducted in 2015 and it concerned both hand hygiene self-assessment framework and hand hygiene audit of practice. These activities were conducted in 2015 between 31 March 2015 and 20 April 2015. Hand hygiene audit was conducted in 6 inpatients wards (Neonatology, Intensive Care Unit, Paediatrics, Surgical, Internal Medicine and Gynaeco-Obstetrics). There were 58 hand hygiene actions from 278 hand hygiene opportunities, with an average of 46 hand hygiene opportunity per ward. The compliance ranged from $1.9 \%$ (Internal Medicine) to $57.8 \%$ (ICU), and the average hand hygiene compliance for the hospital was $20.86 \%$ (Table 4). An improvement of $14.61 \%$ of hand hygiene practice (6.25\% in 2012 to $20.86 \%$ in 2015) was noted. When considering the five moments for hand hygiene, data from 2015 hand hygiene audit showed that 19\% (18/97) performed hand hygiene before touching a patient, 30\% (9/30) practiced hand hygiene before a clean/aseptic procedure, $32 \%$ (6/19) performed hand hygiene after body blood/body fluid exposure, 28\% (25/90) practiced hand hygiene after touching a patient while nobody $(0 / 42)$ performed hand hygiene after touching patient surroundings (Table 4). Intensive Care Unit was the ward who was doing better compared to the other 5 wards with $57.8 \%(26 / 45)$ and the hand hygiene performance was similar for nurses and medical doctors with 58\% (18/31) and 57\% (8/14) respectively (Tables 4-6). The wards like internal medicine, pediatrics and surgical performed poorly with $1.9 \%(1 / 52), 2.4 \%(1 / 42)$ and $6.3 \%$ $(2 / 32)$ respectively (Tables 4 and 6$)$. Alcohol-based handrub (ABHR) was the most used procedures and it was used in $89.66 \%(52 / 58)$ of performed indications, while handwashing with soap and water represented $10.34 \%(6 / 58)$ (Table 5). Looking at hand hygiene practice among professional categories: there were 24.6\% (33/134) actions of nurses' opportunities, $22.7 \%$ (25/110) actions of medical doctors and there was no action among allied health professionals $(0 / 8)$ nor caretakers (0/26) (Table 6). Hand hygiene self-assessment tool was completed by IPC team on 29 October 2015 and the hospital scored

\begin{tabular}{|c|c|c|c|}
\hline Moments & $\begin{array}{c}\text { No. } \\
\text { opportunities }\end{array}$ & $\begin{array}{c}\text { No. } \\
\text { actions }\end{array}$ & Compliance (\%) \\
\hline Before touching patient & 12 & 1 & 8.3 \\
\hline Before clean/aseptic procedure & 3 & 1 & 33.3 \\
\hline After body fluid exposure & 0 & 0 & 0.0 \\
\hline After touching patient & 3 & 0 & 0.0 \\
\hline After touching patient surrounding & 14 & 0 & 0.0 \\
\hline Total & 32 & 2 & 6.25 \\
\hline
\end{tabular}

Table 2: Direct observation of hand hygiene practice in wards of CHUB: May 2012.

\begin{tabular}{|c|c|c|c|}
\hline \multirow{2}{*}{ Component } & 15-May-12 & $\mathbf{2 5 - A u g - 1 3}$ & $\mathbf{2 9 - O c t - 1 5}$ \\
\cline { 2 - 4 } & Sub-total & Sub-total & Sub-total \\
\hline System change & 5 & 35 & 80 \\
\hline Education and training & 50 & 80 & 90 \\
\hline Evaluation and feedback & 10 & 20 & 55 \\
\hline Reminders in the workplace & 5 & 52.5 & 85 \\
\hline Institutional safety climate & 30 & 40 & 45 \\
\hline Total & 100 & 227.5 & 355 \\
\hline Hand hygiene level for the facility & Inadequate & Basic & Intermediate \\
\hline
\end{tabular}

Table 3: Hand hygiene self-assessment at CHUB, 2012-2015.
355. The Hand Hygiene Level for the facility improved from basic to intermediate level (Table 3). The hand washing facilities assessment was conducted during April and May in 2015 and looked at the availability of hand washing basins in different wards and clinical areas of the hospital, the status of the hand washing basins as well as the availability of water at the time the assessment conducted. The findings from that

\begin{tabular}{|c|c|c|c|c|}
\hline Ward & Moments & $\begin{array}{c}\text { No. } \\
\text { opportunities }\end{array}$ & $\begin{array}{l}\text { No. } \\
\text { actions }\end{array}$ & $\begin{array}{c}\text { Compliance } \\
(\%)\end{array}$ \\
\hline \multirow{6}{*}{ Neonatology } & Before touching patient & 40 & 7 & 17.5 \\
\hline & $\begin{array}{l}\text { Before clean/aseptic } \\
\text { procedure }\end{array}$ & 9 & 2 & 22.2 \\
\hline & $\begin{array}{l}\text { After body fluid } \\
\text { exposure }\end{array}$ & 5 & 3 & 60.0 \\
\hline & After touching patient & 31 & 12 & 38.7 \\
\hline & $\begin{array}{l}\text { After touching patient } \\
\text { surrounding }\end{array}$ & 11 & 0 & 0.0 \\
\hline & Total & 96 & 24 & 25 \\
\hline \multirow{6}{*}{$\begin{array}{l}\text { Intensive care } \\
\text { unit }\end{array}$} & Before touching patient & 10 & 8 & 80.0 \\
\hline & $\begin{array}{l}\text { Before clean/Aseptic } \\
\text { procedure }\end{array}$ & 8 & 6 & 75.0 \\
\hline & $\begin{array}{l}\text { After body fluid } \\
\text { exposure }\end{array}$ & 4 & 3 & 75.0 \\
\hline & After touching patient & 20 & 9 & 45.0 \\
\hline & $\begin{array}{l}\text { After touching patient } \\
\text { surrounding }\end{array}$ & 3 & 0 & 0.0 \\
\hline & Total & 45 & 26 & 57.8 \\
\hline \multirow{6}{*}{ Paediatrics } & Before touching patient & 12 & 1 & 8.3 \\
\hline & $\begin{array}{l}\text { Before clean/aseptic } \\
\text { procedure }\end{array}$ & 6 & 0 & 0.0 \\
\hline & $\begin{array}{l}\text { After body fluid } \\
\text { exposure }\end{array}$ & 4 & 0 & 0.0 \\
\hline & After touching patient & 7 & 0 & 0.0 \\
\hline & $\begin{array}{l}\text { After touching patient } \\
\text { surrounding }\end{array}$ & 13 & 0 & 0.0 \\
\hline & Total & 42 & 1 & 2.4 \\
\hline \multirow{6}{*}{ Surgical } & Before touching patient & 9 & 0 & 0.0 \\
\hline & $\begin{array}{l}\text { Before clean/aseptic } \\
\text { procedure }\end{array}$ & 5 & 1 & 20.0 \\
\hline & $\begin{array}{l}\text { After body fluid } \\
\text { exposure }\end{array}$ & 4 & 0 & 0.0 \\
\hline & After touching patient & 12 & 1 & 8.3 \\
\hline & $\begin{array}{l}\text { After touching patient } \\
\text { surrounding }\end{array}$ & 2 & 0 & 0.0 \\
\hline & Total & 32 & 2 & 6.3 \\
\hline \multirow{6}{*}{$\begin{array}{l}\text { Internal } \\
\text { medicine }\end{array}$} & Before touching patient & 24 & 1 & 4.2 \\
\hline & $\begin{array}{l}\text { Before clean/aseptic } \\
\text { procedure }\end{array}$ & 0 & 0 & 0.0 \\
\hline & $\begin{array}{l}\text { After body fluid } \\
\text { exposure }\end{array}$ & 1 & 0 & 0.0 \\
\hline & After touching patient & 15 & 0 & 0.0 \\
\hline & $\begin{array}{l}\text { After touching patient } \\
\text { surrounding }\end{array}$ & 12 & 0 & 0.0 \\
\hline & Total & 52 & 1 & 1.9 \\
\hline \multirow{5}{*}{$\begin{array}{l}\text { Gynaeco- } \\
\text { obstetrics }\end{array}$} & Before touching patient & 2 & 1 & 50.0 \\
\hline & $\begin{array}{l}\text { Before clean/aseptic } \\
\text { procedure }\end{array}$ & 2 & 0 & 0.0 \\
\hline & After touching patient & 5 & 3 & 60.0 \\
\hline & $\begin{array}{l}\text { After touching patient } \\
\text { surrounding }\end{array}$ & 2 & 0 & 0.0 \\
\hline & Total & 11 & 4 & 36.4 \\
\hline Overall & & 278 & 58 & 20.86 \\
\hline
\end{tabular}

Table 4: Hand hygiene audit in six wards of CHUB by 5 moments: 31 March 2015 to 20 April 2015. 
Citation: Hakizimana B (2018) Implementation of the WHO Multimodal Hand Hygiene Improvement Strategy in a Tertiary Academic Hospital in Rwanda. J Infect Dis Med 3: 126. doi: 10.4172/2576-1420.1000126

Page 5 of 8

\begin{tabular}{|c|c|c|c|c|c|c|c|c|c|c|c|c|c|c|c|}
\hline \multirow{2}{*}{ Ward } & \multicolumn{3}{|c|}{ Before touching a patient } & \multicolumn{3}{|c|}{$\begin{array}{l}\text { Before a clean/aseptic } \\
\text { procedure }\end{array}$} & \multicolumn{3}{|c|}{ After body fluid exposure } & \multicolumn{3}{|c|}{ After touching a patient } & \multicolumn{3}{|c|}{$\begin{array}{l}\text { After touching patient } \\
\text { surroundings }\end{array}$} \\
\hline & Ind (No.) & $\begin{array}{l}\text { HW } \\
\text { (No.) }\end{array}$ & HR (No.) & $\begin{array}{l}\text { Ind } \\
\text { (No.) }\end{array}$ & $\begin{array}{l}\text { HW } \\
\text { (No.) }\end{array}$ & HR (No.) & $\begin{array}{l}\text { Ind } \\
\text { (No.) }\end{array}$ & $\begin{array}{l}\text { HW } \\
\text { (No.) }\end{array}$ & HR (No.) & $\begin{array}{l}\text { Ind } \\
\text { (No.) }\end{array}$ & $\begin{array}{l}\text { HW } \\
\text { (No.) }\end{array}$ & HR (No.) & $\begin{array}{l}\text { Ind } \\
\text { (No.) }\end{array}$ & $\begin{array}{l}\text { HW } \\
\text { (No.) }\end{array}$ & HR (No.) \\
\hline Neonatology & 40 & 0 & 7 & 9 & 0 & 2 & 5 & 0 & 3 & 31 & 0 & 12 & 11 & 0 & 0 \\
\hline $\begin{array}{c}\text { Intensive care } \\
\text { unit }\end{array}$ & 10 & 0 & 8 & 8 & 0 & 6 & 4 & 3 & 0 & 20 & 1 & 8 & 3 & 0 & 0 \\
\hline Paediatrics & 12 & 0 & 1 & 6 & 0 & 0 & 4 & 0 & 0 & 7 & 0 & 0 & 13 & 0 & 0 \\
\hline Surgical & 9 & 0 & 0 & 5 & 0 & 1 & 4 & 0 & 0 & 12 & 0 & 1 & 2 & 0 & 0 \\
\hline $\begin{array}{l}\text { Internal } \\
\text { medicine }\end{array}$ & 24 & 1 & 0 & 0 & 0 & 0 & 1 & 0 & 0 & 15 & 0 & 0 & 12 & 0 & 0 \\
\hline $\begin{array}{l}\text { Gynaeco- } \\
\text { obstetrics }\end{array}$ & 2 & 0 & 1 & 2 & 0 & 0 & 0 & 0 & 0 & 5 & 1 & 2 & 2 & 0 & 0 \\
\hline Total & 97 & 1 & 17 & 30 & 0 & 9 & 18 & 3 & 3 & 90 & 2 & 23 & 43 & 0 & 0 \\
\hline Compliance & & 1.0 & 17.5 & & 0.0 & 30.0 & & 16.7 & 16.7 & & 2.2 & 25.6 & & 0.00 & 0.00 \\
\hline \multicolumn{16}{|c|}{ Ind: Indications; No: Number; HW: Hand Washing; HR: Hand Rub } \\
\hline Statistics & (n) & $\%$ & & & & & & & & & & & & & \\
\hline $\begin{array}{c}\text { Total } \\
\text { indications }\end{array}$ & 278 & & & & & & & & & & & & & & \\
\hline Total actions & 58 & 20.86 & & & & & & & & & & & & & \\
\hline Total HW & 6 & 10.34 & & & & & & & & & & & & & \\
\hline Total HR & 52 & 89.66 & & & & & & & & & & & & & \\
\hline
\end{tabular}

Table 5: Hand hygiene audit in 6 wards of CHUB by five moments of hand hygiene and by hand procedure performed: 31 March 2015 to 20 April 2015 .

\begin{tabular}{|c|c|c|c|c|}
\hline Ward & Prof. cat. & No. of opportunities & No. of actions & Compliance (\%) \\
\hline \multirow{3}{*}{ Neonatology } & Nurses & 30 & 11 & 36.7 \\
\hline & Doctors & 40 & 13 & 32.5 \\
\hline & Caretakers & 26 & 0 & 0 \\
\hline \multirow{2}{*}{ Intensive care unit } & Nurses & 31 & 18 & 58 \\
\hline & Doctors & 14 & 8 & 57 \\
\hline \multirow{3}{*}{ Paediatrics } & Nurses & 20 & 1 & 5 \\
\hline & Doctors & 14 & 0 & 0 \\
\hline & Allied health professionals & 8 & 0 & 0 \\
\hline \multirow{2}{*}{ Surgical } & Nurses & 24 & 2 & 8 \\
\hline & Doctors & 8 & 0 & 0 \\
\hline \multirow{2}{*}{ Internal medicine } & Nurses & 22 & 1 & 5 \\
\hline & Doctors & 30 & 0 & 0 \\
\hline \multirow{2}{*}{ Gynaeco-obstetrics } & Nurses & 7 & 1 & 14 \\
\hline & Doctors & 4 & 3 & 75 \\
\hline Overall & & 278 & 58 & 20.86 \\
\hline
\end{tabular}

Table 6: Hand hygiene audit in 6 wards of CHUB by professional categories: 31 March 2015 to 20 April 2015.

\begin{tabular}{|c|c|c|c|c|c|}
\hline$S / N$ & Ward/Dpt & No. beds & $\begin{array}{l}\text { No. hand washing } \\
\text { basins (HWB) }\end{array}$ & $\begin{array}{l}\text { No. HWB in good } \\
\text { conditions }\end{array}$ & $\begin{array}{l}\text { No. HWB with water } \\
\text { available }\end{array}$ \\
\hline 1 & Neonatology & 27 & 5 & 1 & $3 / 5$ \\
\hline 2 & Intensive care unit & 6 & 5 & 3 & $4 / 5$ \\
\hline 3 & Paediatrics & 46 & 17 & 12 & $9 / 17$ \\
\hline 4 & Surgical & 108 & 10 & 0 & $3 / 10$ \\
\hline 5 & Internal medicine & 62 & 5 & 3 & $3 / 5$ \\
\hline 6 & Gynaeco-obstetrics & 66 & 34 & 24 & $5 / 34$ \\
\hline 7 & Ear-Nose-Throat & 8 & 5 & 4 & $0 / 5$ \\
\hline 8 & One stop TB center & 32 & 4 & 4 & $0 / 4$ \\
\hline
\end{tabular}


Citation: Hakizimana B (2018) Implementation of the WHO Multimodal Hand Hygiene Improvement Strategy in a Tertiary Academic Hospital in Rwanda. J Infect Dis Med 3: 126. doi: 10.4172/2576-1420.1000126

Page 6 of 8

\begin{tabular}{|c|c|c|c|c|c|}
\hline 9 & Physiotherapy & 0 & 4 & 2 & $0 / 4$ \\
\hline 10 & Ophthalmology & 9 & 2 & 0 & $0 / 2$ \\
\hline 11 & Dialysis unit & 8 & 2 & 2 & $0 / 2$ \\
\hline 12 & Stomatology & 0 & 5 & 5 & $5 / 5$ \\
\hline 13 & Emergency - Surgical (Old maternity building) & 10 & 21 & 4 & $1 / 21$ \\
\hline 14 & Emergency - Surgical (New building) & 0 & 24 & 24 & $0 / 24$ \\
\hline 15 & Dermatology & 16 & 3 & 3 & $3 / 3$ \\
\hline 16 & OPD - Surgery & 0 & 12 & 6 & $10 / 12$ \\
\hline 17 & Paediatrics - HIV clinic & 0 & 7 & 4 & $6 / 7$ \\
\hline 18 & OPD - Internal Medicine & 0 & 8 & 4 & $5 / 8$ \\
\hline 19 & OPD - Paediatrics & 0 & 6 & 2 & $6 / 6$ \\
\hline 20 & ARV - Adults & 0 & 16 & 12 & $16 / 16$ \\
\hline 21 & Clinic ward & 12 & 8 & 6 & $0 / 8$ \\
\hline 22 & Pharmacy Department & 0 & 6 & 5 & $5 / 6$ \\
\hline 23 & Laboratory - New building & 0 & 6 & 6 & $5 / 6$ \\
\hline 24 & Laboratory - Old building & 0 & 5 & 5 & $3 / 5$ \\
\hline 25 & Operating Theatre - Surgical & 8 & 14 & 9 & $0 / 14$ \\
\hline 26 & Operating Theatre - Ophthalmology & 0 & 2 & 0 & $0 / 2$ \\
\hline 27 & Archiving building & 0 & 3 & 2 & $3 / 3$ \\
\hline 28 & Radiology & 0 & 6 & 4 & $4 / 6$ \\
\hline 29 & Administrative block & 0 & 1 & 1 & $0 / 1$ \\
\hline 30 & Cafeteria & 0 & 3 & 1 & $3 / 3$ \\
\hline 31 & Sterile Service Department & 0 & 0 & 0 & 0 \\
\hline 32 & Laundry & 0 & 0 & 0 & 0 \\
\hline 33 & Public toilets & 0 & 9 & 0 & $0 / 8$ \\
\hline 34 & Mortuary & 0 & 4 & 1 & $4 / 4$ \\
\hline 35 & Incinerator shelter & 0 & 1 & 0 & $0 / 1$ \\
\hline & Total & 418 & 263 & 159 & 106 \\
\hline \multicolumn{2}{|r|}{$\%$} & & & 60.46 & 40.30 \\
\hline
\end{tabular}

Table 7: Status of hand washing basins (HWB) in different wards and clinical areas of CHUB: April-May 2015.

survey showed that $60.46 \%(159 / 263)$ of hand washing basins were in good conditions (means working and not damaged) while water was available in $40.30 \%(106 / 263)$ of hand washing basins (Table 7). The patient wards in CHUB were designed as follows: 16 bedded rooms, 14 bedded rooms, 2 bedded rooms and single room. There were no single hand washing basins in ward to serve for clinical practice for the most of 16 bedded and 14 bedded rooms. The hand washing basin was placed into ensuite facilities (toilets) for the 2 bedded and single rooms. The health professionals used the ensuite facility hand washing basin to wash their hands during healthcare delivery (clean/aseptic procedures). There were some key challenges observed in the hospital such as the design of the hospital that did not took in account the infection prevention and control requirements like the placement of hand hygiene facilities in the right place, the sink: bed ratio that was less than 1:10, lack of a realistic plan to improve the infrastructure in the hospital, patients and caretakers were not really involved in clinical hand hygiene promotion and there was no initiative to support local continuous improvement being applied in the hospital, such as hand hygiene E-learning tools, hand hygiene target to be achieved each year, a system for intra-institutional sharing of reliable and tested local innovations, communications that regularly mention hand hygiene (facility newsletter, clinical meetings, etc.), system for personal accountability, buddy system for new employees, etc.

\section{Discussion}

There is convincing evidence that improved hand hygiene through multimodal implementation strategies can reduce HAI rates [1323]. Although not reporting infection rates several studies showed a sustained decrease of the incidence of multidrug-resistant bacterial isolates and patient colonization following the implementation of hand hygiene improvement strategies. Failure to perform appropriate hand hygiene is considered to be the leading cause of HAI and the spread of multi-resistant organisms, and has been recognized as a significant 
contributor to outbreaks [23-27].

Transmission of healthcare-associated pathogens through contaminated HCWs' hands is the most common pattern in most settings and require five sequential steps: (i) organisms are present on the patient's skin, or have been shed onto inanimate objects immediately surrounding the patient; (ii) organisms must be transferred to the hands of HCWs; (iii) organisms must be capable of surviving for at least several minutes on HCWs' hands; (iv) hand washing or hand antisepsis by the HCWs must be inadequate or omitted entirely, or the agent used for hand hygiene inappropriate; and (v) the contaminated hand or hands of the caregiver must come into direct contact with another patient or with an inanimate object that will come into direct contact with the patient $[21,23]$.

Insufficient or very low compliance rates have been reported from both developed and developing countries. Adherence of HCWs to recommended hand hygiene procedures has been reported as variable, with mean baseline rates ranging from $5 \%$ to $89 \%$ and an overall average of $38.7 \%$ [23].

Defective hand cleansing (e.g. use of an insufficient amount of product and/or an insufficient duration of hand hygiene action) leads to poor hand decontamination. Obviously, when HCWs fail to clean their hands during the sequence of care of a single patient and/or between patients' contact, microbial transfer is likely to occur. Contaminated HCWs' hands have been associated with endemic HAIs and also with several HAI outbreaks [28-33].

It is feasible and possible to implement WHO Hand Hygiene Improvement Strategy in a limited resource hospital and thus, it is possible to improve patient safety at any kind of healthcare facilities whether it is in high or limited resources facilities. The leadership support and ownership is the key for success. However, all the 5 components are not at the same level or the same speed of implementation. The three components which are: system change, training and education and reminders at the work place looked like easy to be implemented and achieved within the short to medium timeframe. However, the evaluation and feedback as well as the institutional safety climate looked to be not easier for early implementation because they require advanced knowledge, skills and expertise as well as IT support. Some good and exciting results were noted such improvement of hand hygiene level of hospital from the basic level to the intermediate level within a three year period, the increased hand hygiene compliance from $6.25 \%$ to $20.68 \%$ and making accessible of alcohol-based hand rub at the point of care. In this study, ABHR was performed in $89.66 \%(52 / 58)$ of all hand hygiene performed actions, while hand washing was $10.34(6 / 58)$. However, hand hygiene compliance among healthcare workers is not acceptable, below $40 \%$ globally [4,9-11]. The conception of the hospital and ward design play a big role in the success of a hand hygiene project and improving patient and staff safety. There should be at least one hand washing basin in patient room and ideally one hand washing basin for every 10 beds. There was no hand washing basin in most of the general wards ( 16 bedded or 14 bedded rooms) and where available ( 2 bedded or single rooms) hand washing basin was placed in ensuite facilities (toilets). It is known that adequate hand hygiene is a major factor in preventing transmission of infections; it is essential that provision of sufficient and appropriate hand hygiene facilities are considered in the early design stage. Hand washing basins should be provided in rooms where procedures are likely to occur, including inpatient rooms, ICU bed bays, treatment and procedure rooms. The type of hand washing basins in clinical areas such as these should be ideally provided with sensor taps, prevent splashing, and be of sufficient size and height above floor level to permit the washing of forearms. In areas with physical barriers, e.g., Emergency Unit cubicles or rooms, a hand washing basin should be accessible within each individual space [22].

\section{Conclusion}

It is feasible and possible to implement WHO Hand Hygiene Improvement Strategy even in healthcare facilities with limited resources. The findings from the study showed the improvement from the basic level to intermediate level of hand hygiene and improvement in hand hygiene compliance of $14.61 \%$ (from $6.25 \%$ to $20.68 \%$ ) in three year period. However the compliance in hand hygiene practice was still low and less than the accepted level of $40 \%$ that was demonstrated to be acceptable and come up with big impact in reducing healthcareassociated infections (HAI) in healthcare settings. The third and fifth strategies (Evaluation and feedback, Institutional Safety Climate) were the two strategies difficult to implement because they require further knowledge, skills and expertise as well as IT to support their implementation. A very poor hand hygiene performance had been observed in Allied Health Professionals and patients care takers. There were no hand washing basins in most of patient wards and clinical areas. The hand washing facilities in the hospital were not adequate and the ones available were not placed in the right place to make hand washing practice easy and accessible for healthcare workers. The assessment of hand washing basins showed that $60.46 \%(159 / 263)$ were in good conditions and water was available for about $40.30 \%(106 / 263)$. There is a need to continue with the implementation of the WHO Multimodal Hand Hygiene Improvement Strategy by sustaining what have been achieved and putting more effort in areas of improvement such developing SMART plans for staff training and education, patient involvement and infrastructure improvement plan. The hospital management should think on how to set up initiatives to support local continuous improvement being applied in the hospital for example: hand hygiene E-learning tools, to establish a hand hygiene institutional target to be achieved each year, a system for intra-institutional sharing of reliable and tested local innovations, establishing communications that regularly mention hand hygiene e.g. facility newsletter, clinical meetings and induction programme for new employees. The hospital infection prevention and control committee and infection control team should plan to conduct other hand hygiene parameters such as the perception of healthcare workers and managers towards healthcareassociated and hand hygiene, hand hygiene supplies consumption (soap, alcohol-based hand rub), evaluation of tolerability of alcoholbased hand rub and gloves use in clinical activities. They should also develop and implement HAI surveillance programme.

\section{Acknowledgements}

The author is grateful for the support from the leadership and managers, medical doctors and nurses of the University Teaching Hospital of Butare.

The author would like to convey his special gratitude to the Infection Contro Team and Infection Control Committee members for their active participation in this project.

My acknowledgement goes to Prof. Alison Hormes, Professor of Infectious Diseases at Imperial College and the Director of Infection Prevention and Control and Associate Medical Director for Imperial College Healthcare NHS Trust and her team for their technical support and knowledge and skills transfer during this project.

\section{References}

1. Prevention of hospital-acquired infections: A practical guide (2002) Geneva World Health Organization.

2. Shiva F, Kamali M, Shirvani F, Armin S, Ghanaiei R, et al. (2014) Hand hygiene compliance by the health care staff in a pediatric hospital. Archives of Pediatric Infectious Diseases 2: e18909. 
Citation: Hakizimana B (2018) Implementation of the WHO Multimodal Hand Hygiene Improvement Strategy in a Tertiary Academic Hospital in Rwanda. J Infect Dis Med 3: 126. doi: 10.4172/2576-1420.1000126

Page 8 of 8

3. Lam BC, Lee J, Lau YL (2004) Hand hygiene practices in a neonatal intensive care unit: A multimodal intervention and impact on nosocomial infection. Pediatrics 114: e565-e571.

4. Erasmus V, Daha TJ, Brug $\mathrm{H}$, Richardus JH, Begrendt MD, et al. (2010) Systematic review of studies on compliance with hand hygiene guidelines in hospital care. Infection Control and Hospital Epidemiology. 31: 283-294.

5. Huis A, Schoonhoven L, Grol R, Donders R, Hulscher M, et al. (2013) Impact of a team and leaders-directed strategy to improve nurses' adherence to hand hygiene guidelines: A cluster andomized trial. Int J Nurs Stud 4: 464-474

6. Burke JP (2003) Infection control: A problem for patient safety. N Engl J Med 348: 651-656.

7. Allegranzi B, Bagheri Nejad S, Combescure C, Graafmans W, Attar H, et al. (2011) Burden of endemic healthcare-associated infection in developing countries: Systematic review and meta-analysis. Lancet 377: 228-241.

8. http://www.who.int/gpsc/ssi-prevention-guidelines/en/

9. Lee A, Chalfine A, Daikos GL, Garilli S, Jovanovic B, et al. (2011) Hand hygiene practices and adherence determinants in surgical wards across Europe and Israel: A multicenter observational study. Am J Infect Control 39: 517-520.

10. Marra AR, Guastelli LR, de Araújo CM, dos Santos JL, Filho MA, et al. (2011) Positive deviance: A program for sustained improvement in hand hygiene compliance. Am J Infect Control 39: 1-5.

11. Pittet D, Hugonnet S, Harbarth S, Mourouga P, Sauvan V, et al. (2000) Effectiveness of a hospital-wide programme to improve compliance with hand hygiene. Infection Control Programme. Lancet 356: 1307-1312.

12. Allegranzi B, Gayet-Ageron A, Damani N, Bengaly L, McLaws ML, et al. (2013) Global implementation of WHO's multimodal strategy for improvement of hand hygiene: A quasi-experimental study. Lancet Infect Dis 13: 843-851.

13. Allegranzi B, Pittet D (2009) The role of hand hygiene in healthcare-associated infection prevention. J Hosp Infect 73: 305-315.

14. World Health Organization (2009) A Guide to the Implementation of the WHO Multimodal Hand Hygiene Improvement Strategy. Geneva, Switzerland.

15. http://www.who.int/gpsc/5may/tools/evaluation_feedback/en/index.html.

16. World Health Organization (2009) WHO Guidelines on Hand Hygiene in Health Care. First Global Patient Safety Challenge Clean Care is Safer Care.

17. Sax H, Allegranzi B, Chraïti MN, Boyce J, Larson E, et al. (2009) The World Health Organization hand hygiene observation method. Am J Infect Control 37: 827-834.

18. World Health Organization (2011) The African Partnership for Patient Safety Planning Framework.

19. Alsubaie S, Maither ab, Alalmaei W, Al-Shammari AD, Tashkandi M, et al. (2013) Determinants of hand hygiene noncompliance in intensive care units. Am J Infect Control 41: 131-135.
20. Pittet D, Boyce JM (2001) Hand hygiene and patient care: Pursuing the Semmelweis legacy. The Lancet Infectious Diseases 1: 9-20.

21. Pittet D, Allegranzi B, Sax H, Dharan S, Pessoa-Silva CL, et al. (2006) Evidence-based model for hand transmission during patient care and the role of improved practices. Lancet Infect Dis 6: 641-652.

22. International Health Facility Guidelines. Hand Hygiene. Part B: Version 2017.

23. http://www.who.int/gpsc/5may/tools/who_guidelines-handhygiene_summary pdf?ua=1.

24. Brown SM, Lubimova AV, Khrustalyeva NM, Shulaeva SV, Tekhova I, et al (2003) Use of an alcohol-based hand rub and quality improvement interventions to improve hand hygiene in a Russian neonatal intensive care unit. Infect Control Hosp Epidemiol 24: 172-179.

25. Gordin FM, Schultz ME, Huber RA, Gill JA (2005) Reduction in nosocomial transmission of drug-resistant bacteria after introduction of an alcohol-based handrub. Infect Control Hosp Epidemiol 26: 650-653.

26. Trick WE, Vernon MO, Welbel SF, Demarais P, Hayden MK, et al. (2007) Multicenter intervention program to increase adherence to hand hygiene recommendations and glove use and to reduce the incidence of antimicrobial resistance. Infect Control Hosp Epidemiol 28: 42-49.

27. Girou E, Legrand P, Soing-Altrach S, Lemire A, Poulain C, et al. (2006) Association between hand hygiene compliance and methicillin-resistant Staphylococcus aureus prevalence in a French rehabilitation hospital. Infect Control Hosp Epidemiol 27: 1128-1130.

28. Foca M, Jakob K, Whittier S, Della Latta P, Factor S, et al. (2000) Endemic Pseudomonas aeruginosa infection in a neonatal intensive care unit. $\mathrm{N}$ Engl $\mathrm{J}$ Med 343: 695-700.

29. Sartor C, Jacomo V, Duvivier C, Tissot-Dupont H, Sambuc R, et al. (2000) Nosocomial Serratia marcescens infections associated with extrinsic contamination of a liquid nonmedicated soap. Infect Control Hosp Epidemio 21: 196-199.

30. Boyce JM, Potter-Bynoe G, Opal SM, Dziobek L, Medeiros AA (1990) A common-source outbreak of Staphylococcus epidermidis infections among patients undergoing cardiac surgery. J Infect Dis 161: 493-499.

31. Zawacki A, O'Rourke E, Potter-Bynoe G, Macone A, Harbarth S, et al. (2004) An outbreak of Pseudomonas aeruginosa pneumonia and bloodstream infection associated with intermittent otitis externa in a healthcare worker. Infect Control Hosp Epidemiol 25: 1083-1089.

32. El Shafie SS, Alishaq M, Leni Garcia M (2004) Investigation of an outbreak of multidrug resistant Acinetobacter baumannii in trauma intensive care unit. $J$ Hosp Infect 56:101-105.

33. https://dailymed.nlm.nih.gov/dailymed/dr. 